\title{
'N ONDERSOEK NA DIE PERSOONLIKE ERVARING VAN BEVOEGDHEID VAN STUDENTVROEDVROUE IN DIE UITVOER VAN EPISIOTOMIE-HEGTINGS
}

\author{
ME Bester en HA Lamprecht
}

\begin{abstract}
A non-xperimental, descriptive study was conducted to determine the knowledge and efficiency of student midwives in the performing of episiotomy repairs. A questionnaire was administered to 50 students from the two universities and affiliated colleges in the Western Cape.
\end{abstract}

Sixty percent $(N=30)$ of the respondents regarded themselves as efficient. However. only one of these respondents had all the necessary knowledge concerming perineal repairs with $15(50 \%)$ of these respondents "knowledge that could be considered as insufficient.

Fifty-four percent of the respondents $(N=27)$ considered it necessary to repair more thant 3 episiotomies in order to feel confident.

\section{OPSOMMING}

'n Nie-eksperimentele, beskrywende ondersoek is onderneem om die kennis en vaardighedi van studentvroedvroue ten opsigte van die uitvoer van episiotomie-hegtings, vas te stel. Vraelyste is deur 50 studentroedvroue verbonde aan die 2 universiteite en geaffilieerde kolleges in die Wes-Kaap, ingevul.

Sestig persent van die vroedvroue $(N=30)$ hel hulle self as bevoeg beskou. Slegs een van hierdie respondente se kennis was korrek

Vier-en-vyfig persent van die respondente $(N=27)$ was van mening dat dit nodig was om meer as 3 episiolomie-hegtings in te oefen, alvorens die vroecturou haarself as bevoeg kon beskou.

Dit wil dus voorkom asof daar 'n groal leemte ten opsigte van die teoretiese kennis, sowel as praktiese, kliniese begeleiding van studente ten opsigue van die uitwoer van episiotomie-liegtings, bestaan.

\section{INLEIDING}

Die uitvoer van episiotomies het 'n algemene verloskundige praktyk geword. Dit is egter insiggewend dat relatief $\mathrm{min}$ studies gedoen is om die bevoegdheid van vroedvroue met betrekking tot ' $n$ prosedure wat major implikasies inhou, te evalueer (Alexander, Levy \& Roch, 1990: 129).

Sleep (in Alexander etal, 1990:13) stel trouens die vraag oor of daar enersyds beleid bestaan in verloskundige eenhede oor wie verantwoordelik is om vroedvroue die tegniek van hegting aan te leer, en andersyds of geleenthede bestaan om hegtingsvaardighede op te dateer en nuwe tegnieke aan te leet

Enkin, Keirse en Chalmers (1989:242) meld dat die vaardighede van die persoon wat die hegting doen, meer bepalend is vir minimale kort- en langtermyn komplikasies, as die materiaal of spesifieke tegnieke wat gebruik word. Baie min wetenskaplike bewyse bestaan egter oor die verband tussen vaardigheid en die ongewenste effekte wat met perineale hegtings, geassosier word Enkin et al, (1990:242) meld dat ervaring nie noodwendig beter resultate impliseer nie - ".. the same mistakes may be made with increasing confidence..."

Dit blyk dat navorsing oor opleiding in die herstel van perineale skade, baie beperk is. ' $n$ Tradisionele benadering is steeds soos beskryf deur Enkin et al, (1990:242), “... see three, do three, and now you are on your own".

Die riglyne ook binne die Suid-Afrikaanse konteks is baie arbitrêt. Sedert 1974 word daar in die regulasies van die Suid-Afrikaanse Raad op Verpleging, voorsiening gemaak dat hegting van episiotomies deel van die vroedvroupraktyk word.

Tans is die riglyn wat gestel word dat die "student 'n hegting, insluitende cerste- en tweedegraadse skeure of ' $n$ episiotomie moet kan heg". Elke opleidingsinstansie het die reg om self die spesifieke vereistes daar te stel

Vroedvroukundigheid word ten opsigte van verskeie vaardighede bevraagteken Sommige meningsvormers is selfs cortuig dat die hegting van episiotomies sowel as eersteen tweedegraadse skeure nie deel van die bestek van praktyk en beslis nie deel van die vroedvrou se opleiding, moet behels nie

Sodanige siening is volgens die navorsers egter kortsigtig en hou me met die eise van die praktyk tred nie. Daar is nie voldoende geneeshere, veral nie in perifere verlossingscenhede beskikbaar om die hegtings te doen nie. Die mediese student se vaardigheid is $\infty \mathrm{k}$ nie bo verdenking nie, en dit is in elk geval meestal die vroedvrou wat die mediese student in die hegtingstegniek moet onderrig

Die navorsers aanvaar egter dat daar wel moontlik probleme ten opsigte van die uitvoer van hegtings deur studentvroedvroue, mag bestaan. In die lig hiervan is die projek onder bespreking geloods, naamlik om die studentvroedvrou se kennis en eie ervaring van haar bevoegdheid, te evalueer

\section{DOEL VAN DIE NAVORSING}

Die doel van die navorsing was

- Om vas te stel tot watter mate die studentvroedvrou haarself as bevoeg beskou om ' $n$ episiotomie-hegting korrek en met selfvertroue, te kan uitvoer.

- Om die studentvroedvrou se teoretiese onderbou in die uitvoer van episiotomies, te evalueer,

- Om faktore te identifiseer wat moontlik kan bydra tol die ervaring van bevoegdheid. 
OPERASIONELE

\section{KONSEPFORMULERING}

Studentvroedvrou verwys na enige persoon besig met verloskundige opleiding. Dit sluit dus geregistreerde algemene verpleegkundiges sowel as student-verplecgkundiges in

\section{Strukture Betrokke By Episiotomie}

Vel, vaginale epiteel, oppervlakkige transvers perineale spiere en in geval van ' $n$ diep episiotomie, kan die levator ani ook betrek word.

\section{Korrekte HegtingsmateriaaVnaald}

Vir die doel van die navorsing, is volstaan by chroom 0 op 'n ronde naald vir hegting van die vaginale epiteel en spierlag en chroom 0 op 'n snynaald (of rugsnynaald) vir hegting van die vel.

Bogenoemde is gebruik as vertrekpunt aangesien dit die enigste hegtingsmaterial wat in die bepaalde inrigting gebruik word.

\section{Korrekte Tipe Steke}

Vir die doel van die navorsing, is volstaan by die gebruik van 'n enkel steek by die Apeks van die insnyding gevolg deur aneenlopende steke in die vaginale epiteel tot by die carunculae myrtiformis, " $n$ "syfer 8-steek/steke" vir hegting van die spierlaag of onderbroke diep steke, en onderbroke enkelsteke of onderbroke, "matrassteke" vir hegting van die vel.

\section{METODOLOGIE}

'n Nie-eksperimentele beskrywende opnamemetode is gevolg. "n Vraelys bestaande uit dichotomiese, veelkeuse en oop-einde vrae is deur die navorsers ontwerp. Die inhoudsgeldigheid van die vraelys is deur middel van porturgroepevaluering bevestig

'n Groep van 25 studente vertonde an die kolleges en 25 studente verbonde aan die

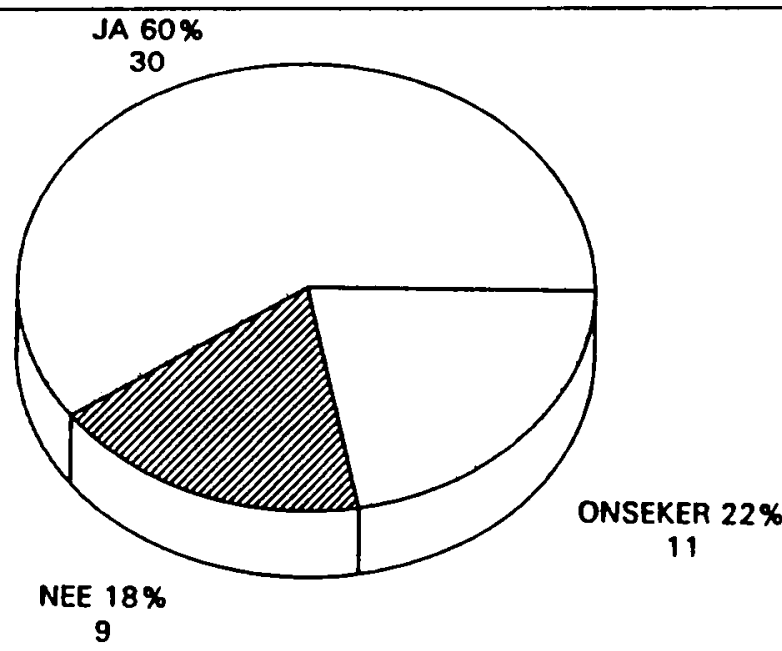

Figuur 1: Eplelotomio-hegtings vole bevoegd - Jullo-Soptember $1893(\mathbf{N}=50)$ universiteite is betrek. Hiedie proefpersone is ewekansig geselektoer.

Insluitingsloriteria was dat die student ten tyde van die navorsing in die praktyk werksaam moes wees en reods minstens cen hegting onderneem het.

Die enigste uitsluitingskriterium was indien die student hasr verloskunde-kursus herhaal het. Die navorsers was van mening dat herhaling van teoretiese en praktiese aspekte, moontlik die student se evaring van haar bevoegdheid, kon beinvloed het

Die vraelyste is individueel aan studente oorhandig en die voltooide vraelyste is onmiddellik weer ontvang om moontlike kontaminasie te beperk.

Toestemming vir die uitvoet van die projek is vanaf die Hoof Mediese Superintendent, Tygerberghospitaal, verkry.

\section{BEVINDINGE}

\section{Biografiese Besonderhede}

Van die respondente, was $50 \%(\mathrm{~N}=25)$ vierdejaarstudente. Drie van die studente $(6 \%)$ het die 1-jasr Diploma in Verloskunde

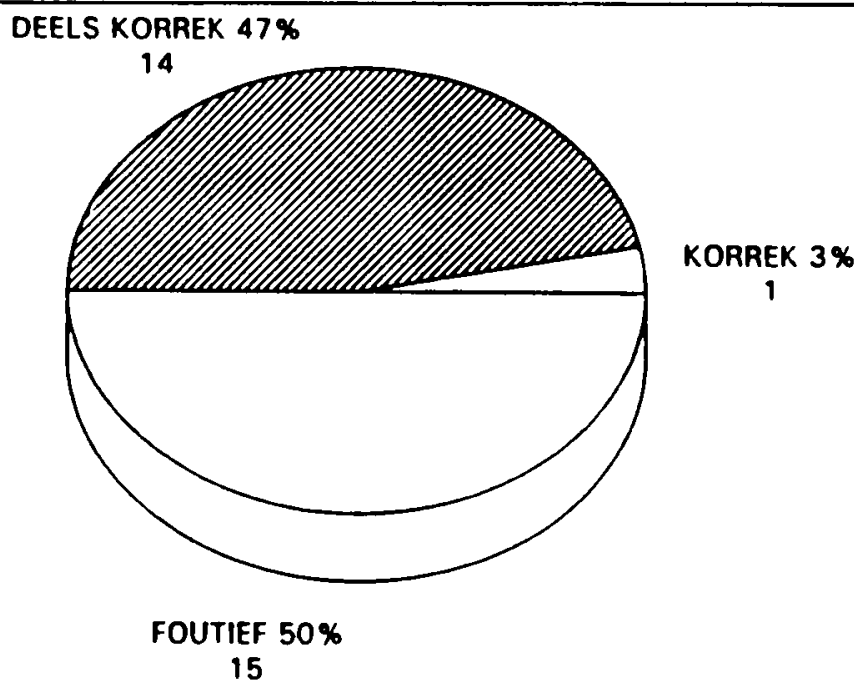

Figuur 2: Eplalotomle-hegtings Kennls korrek - Voel bevoegd Julie-Soptember $1993(\mathrm{~N}=30)$ gevolg, terwyl die ander 22 studente derdejagr studente in verlosicunde was.

In $60 \%(\mathrm{~N}=30)$ gevalle was die gemiddelde tydperk van praktykervaring in die krasmsaal an/of perifere krameenhede, tussen sewe en agt weke. Een-en-twintig van die respondente $(58 \%)$, was reeds by twee geleenthede of meer m die kraamsaal en of perifere kraameenhede, werksagm.

\section{Opleidingsvereistes}

Vrae is gestel oor wat die onderskeie opleidingsinstansies van die studente verwag ten opsigte van vooraf-demonstrasies en vardigheid in hegtings. Die navorsers is bewus daarvan dat hierdie inligting nie noodwendig akurat is en die siening van die onderskeie opleidingsinstansie verteenwoordig nie. Vir die doel van die projek was die navorsers van mening dat die student se siening en kennis van vereistes, belangrik was.

Al die studente van die universiteite het aangetoon dat drie demonstrasies ' $n$ voorvereiste is alvorens hulle self hegtings mag uitvoer. Studente verbonde an een van die kolleges, was onseker ten opisgte van enige vereistes. Studente vertonde aan die ander kollege het angetoon dat hulle two hegtings moes sien voordat hulle die prosedure kon heg. Die l-jaar kursus studente het angetoon dat hulle self kon besluit of hulle cers 'n demonstrasie wil sien alvorens hulle kon heg

Vyf-en-veertig van die respondente ( $90 \%$ ) het aangetoon dat hulle hierdie demonstrasies as baue nuttig an noodsaaklik beskou het. Dit is unsiggewend dat vier van die vyf respondente wat hierdie demonstrasies as "tydmors" beskou heh se kennis foutief en onvolledig was terwyl drie van hiendie vier respondente angetoon het dat hulle na vyf hegtungs, nog hulp benodig het

Dit het geblyk dat die universiteite onderskeidelik vyf epısiotomie-hegtings vereis terwyl die kolleges slegs twee hegtings vereis. Die hegling van cerste graadse skeure 
word nie darr die universiteite as deel van die "vyf hegtings" vereis nie. Een van die universiteite het wel die hegting van tweedegrasdse skeure as doel van die vereiste aantal hegtings aanvaar. Onsekerheid het by die studente van die kolleges bestaan oor of die hegting van skeure as deel van die vereiste praktika aanvaar word.

\section{Kennisvlak}

Slegs vyf van die respondente $(10 \%)$ het die strukture korrek geidentifiseer. Vier van hierdie respondente was vanuit een universiteit afkomstig.

Ten opsigte van die tipe hegtingsmateriaal, het $48 \%(\mathrm{~N}=24)$ die korrekte materiaal getdentifiseer terwyl $92 \%(\mathrm{~N}=46)$ die korrekte tipe(s) naalde geldentifiseer. Negentien van die respondente $(79 \%)$ is deur die universiteite verteenwoordig.

Dertig van die respondente $(60 \%)$ het die korrekte tipes steke geidentifiseer terwyl een-en-twintig van hierdie studente aan die universiteite verbonde was.

Slegs $8 \%(N=4)$ van die respondente het aangedui dat steriele hegtingstegnieke nie nodig is nie en dat dit voldoende is om chinurgies skoon te werk.

Ses-en-veertig (92\%) van die respondente het aangedui dat 'n medio-laterale episiotomie geknip wword, wat trovens ook die enigste tipe episiotomie is wat by die betrokke inrigting uitgevoer word

\section{Vorige Blootstelling}

Ses-en-dertig van die respondente $(72 \%)$ het reeds in trauma-afdelings hegtings gedoen alvorens hulle in die verloskunde-afdelings gewerk het. Van hierdie respondente, was $61 \% \quad(\mathrm{~N}=22)$ universiteitstudente. Laasgenoemde impliseer dat $88 \%(N=22)$ van die universiteitsstudente voor hulle eerste plasing binne die verloskunde-afdelings, reeds in die trauma-afdeling, algemene hegtings gewerk het.

Nege-en-twintig van die respondente (58\%) het vooraf in gesimuleerde omstandighede die hegting van ' $n$ episiotomie geoefen. Drie-en-twintig van hierdie respondente $(79 \%)$ het dit as van waarde beskou.

\section{Begeleiding}

Agt-en-dertig van die respondente (76\%) het angedui dat die geregistreerde vroedvroue in die verloskunde-afdelings verskillende tegnieke aan die studente demonstreer. Twee-en-twintig ( $58 \%$ ) van hierdie respondente het angedui dat hulle die verskillende tegnieke as verwartend ervaar het. Agt-en-dertig van die respondente (76\%) het aangedui dat dit noodsaaklik is dat die geregistreerde vroedvroue censtemmigheid moet bereik ten opsigte van die aanvaabare hegtingstegnicke.

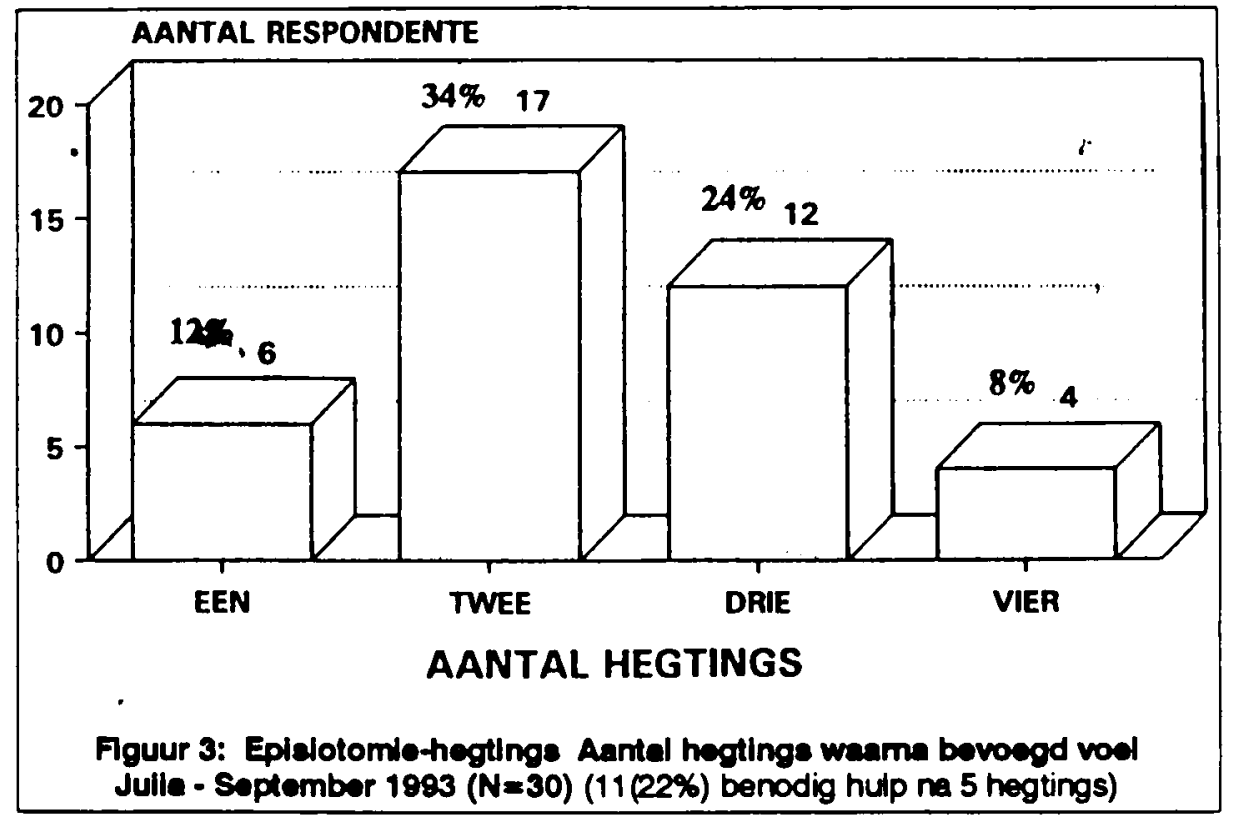

Van die respondente het $48 \%(\mathrm{~N}=24)$ aangedui dat dit maklike was om in die kraamsaal as by die vroedvrou-cenhede die hegtingstegniek aan te leer. Dit was ' $n$ interessante bevinding aangesien die algemene siening bestam dat daar weens ' $n$ kleiner werkslading, meer tyd by die cenhede vir opleiding beskikbaar is.

\section{Bevoegdheid}

Uit figuur 1 blyk dit dat $60 \%(\mathrm{~N}=30)$ van die respondente bevoeg gevoel het om episiotomies met welslae te heg, teenoor 11 van die respondente (22\%) wat onseker, en 9 (18\%) van die respondente wat totaal onbevoeg daaromtrent gevoel het.

Figuur 2 dui bogenoemde 30 respondente se teoretiese kennis ten opsigte van episiotomie-hegtings asm. Slegs een (3\%) van die respondente se kennis was ten volle korrek, terwyl 15 (50\%) van die respondente se kennis suboptimaal en onvoldoende was.

Dit is ' $n$ baic kommerwekkende bevinding, aangesien hierdie spesifieke studente hulleself as bevoeg beskou het om aan hulle medestudente die korrekte tegniek te demonstreer.

Uit figuur 3 kan afgelei word dat $54 \%(N=27)$ van die respondente van mening was dat dre of meer hegtings uitgevoer moet word alvorens bevoegdheid bereik kan word Ses (12\%) van die respondenic was van mening dat slegs een hegting genoegsaam is, terwyl 17 (34\%) van die respondente twee hegungs as genoegsaam aangedu het.

\section{Algemene Kommentasr}

Die studente het aangedui dat hulle graag meer begeleiding en hulp van die kliniese geregistreerde vroedvroue in die praktiese situasie sou wou geniet.

Die studente het verder aangedui dat die geregistreerde vroedvrouc met tussenposes by die student moet "inloer" as ondersteuning en hulle nie vir die prosedure alleen moet laat totdat die hegting aan die einde gekontroleer word nie.

Aansluitend hierby, is die studente van mening dat die doserende personeel ook meer opvolgwerk in die praktyk moet doen. Die studente besef self dat die enigste wyse waarop hulle vaardigheid kan verloy, deur middel van genoegsame oefening is. Dit impliseer dus dat alle moontlike hegtingsgeleenthede angegryp moet word.

Wa duidelik uit die kommentaar geblyk het, is dat studente ' $n$ behoefte het om die rasional van sekere aksies te weet. Dit is dus belangrik dat alle opleidingspersoneel ten volle in die onderliggende redes en beginsels van hegtings onderleg moet woes en die rasional van sekere aksies moa kan verduidelik.

\section{GEVOLGTREKKINGS}

Weens die beperkte aantal 1-jagr studente wat weens logistieke redes in die studie ingesluit is, is dit nie moontlik om vergelykings tussen die 1-jaar en 4-jaar studente te kan maak me.

Dit blyk dat in die geheel gesien die universiteitstudente se kennis wel beter as die van die kollegestudente was. Die navorsers wil dit duidelik stel dat alhoewel die aanname me gemaak kan word dat universiteitstudente dus meer vaardig is nie, die gebrek aan kennis tog kommerwekkend is, aangesien die studentvroedvrou van vandag die geregistreerde vroedvrou van die toekoms is. Dit is uit 'n didaktiex oogpunt ongewens om 'n onkundige learmeester te hé!

Faktore wat geidentifiseer is as bydraend tot die student se selfvertroue en gevoel van bevoegdheid, is:

- Vorige blootstelling aan hegungs in die trauma- afdelings,

- Inoefening in simmulasie-omstandighode, 
- Demonstrasies in die kliniese praktyk alvorens die student vir die eerste keer heg;

- Konsekwentheid in hegtingstegnieke deur persone in die praktyk,

- Deurlopende ondersteuning in die praktyk; en

- 'n Minimum van 3-4 hegtings wat uitgevoer moet word as ' $n$ voorvereiste.

\section{AANBEVELINGS}

Daar word aanbeveel dat alle studente voor hulle eerste plasing binne die verloskunde-afdelings, eers hegtings in ' $n$ algemene trauma-afdeling moet doen ten einde basiese hegtingstegnieke aan te leer.

Die siening dat ' $\mathrm{n}$ minimum van twee hegtings wat die hegting van skeure insluit, as ' $n$ opleidingsvereiste gestel word moet enstig bevraagteken word en aandag geniet.

Navorsing behoort onderneem te word om die student se vaardigheid binne die praktyk te evalueer. Hierdie projek behoort ook na ander kategoriee van verpleegpersoneel en gesondheidswerkers, uitgebrei te word.

Die moontlikheid van indiensopleiding en evaluering van geregistreerde vroedvroue se vaardigheid ten opsigte van episiotomiehegtings, moet ondersoek word. Vaardigheid in so "n "kemaspek" behoort met vrug in " $n$ akkrediteringsprogram ingesluit te kan word.

Meer gestruktureerde begeleiding en ondersteuning van die studentvroedvrou in die kliniese praktyk deur doserende en kliniese praktisyns, moet as ' $n$ prioriteit aangespreek te word.

\section{SLOT}

In hierdie studie is die persoonlike opinie van die student se vaardigheid en bevoegdheid in die hegting van episiotomies verky. Daar is aangetoon dat die studente se kennis en ervaring onvoldoende is. Daar word aanbeveel dat die vereistes wat aan studentvroedvroue in die verband van verpligte, voorgeskrewe episiotomiehegtings, dringend aangespreek moet word. Verdere navorsing behoort onderneem te word om die student se vaardigheid met behulp van 'n objektiewe meetinstrument, te evalueer.

Die begeleiding van studente is as ' $m$ prioriteit uitgewys en soos deur vorige studies oor ander kliniese vaardighede, is aangetoon dat hierdie leemte dringend aangespreek moet word.

\section{BRONNELYS}

Alexander J., Levy V. \& Roch S. (1990): Intrapartum Care. London: Macmillan

Alexander J., Levy V. \& Roch S. (1990): Posmatal Care. London: Macmillan.

Beal M.W. (1984): Nurse-Midwifery Intrapartum Management. Journal of Nurse-Midwifery, 29(1):13-19.

Cogan R. \& Edmunds E.P. (1978): The Unkindest Cut? Journal of NurseMidwifeny, xxiii:17-21.
Enkin M, Keirse MJ.N.C. \& Chalmers I (1989): A guide to Effective Care in Pregnancy and Childbirth. Oxford: Oxford University Press.

Faulkner A. \& Murphy-Black T. (1990): Excellence in Nursing. The Research Route. Midwifery. London: Scutari Press.

Fischer S.R (1979): Factors associated with the occurrence of perineal lacerations. Joumal of Nurse-Midwifery, 24(1): 18-26.

Sellers P.M. (1993): Midwifery. Volume I. Cape Town: Creda Press.

Tew M (1990): Safer Childbirth? London: Chapman \& Hall.

\section{M.E. BESTER M.CUR (U Stel.) Senior Lektrise Universiteit van Stellenbosch}

H.A. Lamprecht B.CUR Nerloskunde en Neonatologie) Universiteit van Stellenbosch 